\title{
ATIVIDADE OVICIDA E LARVICIDA DO EXTRATO HIDROALCOÓLICO DE ARTEMISIA ANNUA SOBRE Haemonchus contortus
}

(Ovicidal and larvicidal activity of Artemisia annua hydroalcoholic extract against Haemonchus contortus)

Lew Kan Sprenger ${ }^{1}$, Juliana Bello Baron Maurer, Selma Faria Zawadzki Baggio, Pedro Melillo de Magalhães, Marcelo Beltrão Molento

\footnotetext{
${ }^{1}$ Correspondência: lew.sprenger@gmail.com
}

RESUMO: Haemonchus contortus é responsável por causar enorme prejuízo econômico na produção de pequenos ruminantes, retardando o crescimento e causando anemia em animais infectados. $O$ objetivo deste trabalho foi determinar a eficácia in vitro do extrato hidroalcoólico de Artemisia annua frente a estágios de vida livre deste parasito. O fitoterápico foi produzido com 7 dias de percolação a $4^{\circ} \mathrm{C}$, sendo posteriormente liofilizado. Foram realizados o teste de eclodibilidade de ovos (TEO) e o teste de desenvolvimento larval (TDL), com concentrações crescentes $(0,78$ a $50 \mathrm{mg} / \mathrm{mL})$ em seis repetições. Para analisar a composição química do fitoterápico, procedeu-se a marcha fitoquímica completa. $\mathrm{O}$ produto obtido a partir da $A$. annua apresentou eficácia de $93,22 \%( \pm 1,87)$ no TEO, já no TDL a eficácia foi de 90,33\% ( $\pm 0,27)$, ambos na concentração de $50 \mathrm{mg} / \mathrm{ml}$. Nas análises fitoquímicas, foram encontrados diversos compostos que podem ter contribuído com o efeito anti-helmíntico, tanto direta como indiretamente. Os dados da marcha fitoquímica, aliados aos resultados dose-dependentes obtidos nos testes in vitro evidenciam que o extrato produzido possui potencial para combater $\mathrm{H}$. contortus. Novos estudos devem ser realizados buscando maximizar a eficácia deste extrato.

Palavras-chave: Controle alternativo; etnoveterinária; fitoterapia; infecção parasitária

ABSTRACT: Haemonchus contortus is responsible for significant economic losses in sheep and goat production, resulting in low growth and anaemia in infected animals. The aim of this study was to determine the in vitro efficacy of hydroalcoholic extract of Artemisia annua against free-living stages of this parasite. The herbal material was produced by leaving the solution for 7 days (extraction period) at $4^{\circ} \mathrm{C}$ and latter the material was lyophilized. After this, the product was used for the egg hatch test (EHT) and the larval development test (LDT) in different concentrations $(0.78$ to $50 \mathrm{mg} / \mathrm{mL})$ with six replicates. A complete phytochemical screening was performed to analyze the materials' chemistry composition. Artemisia annua had an efficacy of $93.22 \%( \pm 1.87)$ using the EHT and of $90.33 \%( \pm 0.27 \%)$ when using the LDT test, both in concentration $50 \mathrm{mg} / \mathrm{ml}$. Phytochemical tests showed few chemical compounds that could exert anthelmintic properties. The results obtained with the biochemical tests together with the dose-dependent effect found in in vitro tests demonstrate that the $A$. annua extract used has the potential to be a good drug candidate against $H$. contortus. Further studies should be conducted to maximize the effectiveness of the extractions from $A$. annua.

Key Words: Alternative control; ethnoveterinary; herbal medicine; parasitic infection 


\section{INTRODUÇÃo}

A produção de pequenos ruminantes no Brasil possui grande importância econômica, gerando renda a milhares de famílias, todavia possui alguns entraves para sua expansão, devido ao manejo sanitário insuficiente, o fator mais importante. A infecção por Haemonchus contortus consolida-se como a principal doença parasitária, causando prejuízos devido a anorexia, apatia, aumento da conversão alimentar, comprometimento da função reprodutiva, diminuição da produção e perda de peso em animais infectados (Nery et al., 2010).

O controle dessa parasitose é realizado, geralmente, como o uso indiscriminado de anti-helmínticos, sem orientação técnica e sem considerar os fatores epidemiológicos (Andrade et al. 2014). Este modelo de utilização favoreceu a seleção e a propagação da população parasitária resistente, além da deposição de resíduos dos medicamentos no meio ambiente $e$ aumento dos custos de produção, principalmente com a aquisição dos fármacos (Molento, 2005).

Devido aos problemas citados, diversas tecnologias estão sendo desenvolvidas, sendo o uso de fitoterápicos o que possui resultados mais promissores (Costa et al., 2008). 0 Brasil possui a maior diversidade genética vegetal do mundo e o uso desses medicamentos está amplamente difundido na população. Dentre as vantagens do seu uso, destaca-se a facilidade de aquisição, o baixo custo e pouco ou nenhum efeito tóxico ambiental.

Dentre as diversas plantas que estão sendo estudas atualmente, a
Artemisia annua destaca-se em pesquisas relacionadas ao controle parasitário animal (Brisibe et al., 2008). Popularmente conhecida como Artemísia ou Erva-de-São-João, é uma planta de origem chinesa, cultivada por determinados centros de pesquisas nacionais. Possui atividade frente a diversas enfermidades, sendo que em parasitologia, os extratos produzidos a partir da planta já apresentaram efeitos comprovados frente a diversos parasitas, como: Schistosoma japonicum e S. mansoni, Clonorchis sinensis, Fasciola hepatica, Opisthorchis viverrini, Leishmania sp., Trypanosoma sp. e Eimeria sp. (Keiser \& Utzinger, 2007; Brisibe et al., 2008).

O presente estudo foi desenvolvido com o objetivo de avaliar a eficácia do extrato hidroalcoólico de $A$. annua em fases de vida livre de $H$. contortus, utilizando testes in vitro.

\section{MATERIAL E MÉTODOS}

Material botânico. Amostras de folhas de $A$. annua foram coletadas no Centro Pluridisciplinar de Pesquisas Químicas, Biológicas e Agrícolas (CPQBA) da Universidade de Campinas (UNICAMP), em Paulínia, SP. A espécie está depositada no herbário da instituição, sob o número 979. Após a colheita, as folhas foram secadas a sombra, em temperatura ambiente e trituradas em moinho de facas, sendo posteriormente armazenadas ao abrigo da luz e umidade.

Obtenção do extrato. Para a produção do extrato hidroalcoólico de sete dias (H.7), utilizou-se um frasco de cor âmbar, no qual foram colocadas $64 \mathrm{~g}$ de folhas junto com $640 \mathrm{~mL}$ de álcool $80 \%(\mathrm{v} / \mathrm{v})$, o qual ficou armazenado em 
refrigerador a $4^{\circ} \mathrm{C}$ por sete dias. Durante o período, houve agitação periódica do conteúdo. Em seguida foi realizada filtração, com auxílio de uma bomba de vácuo, em funil com papel filtro. O extrato foi concentrado em evaporador rotatório, sob pressão reduzida e à temperatura de $28^{\circ} \mathrm{C}( \pm 2)$, para posteriormente liofilização.

\section{Análises}

fitoquímicas.

Posteriormente se realizou a marcha fitoquímica qualitativa descrita por Matos (1998) com o objetivo de verificar a presença de metabólitos secundários (fenóis, taninos, antocianinas, antocianidinas, leucoantocianidinas, esteróides, triterpenos, saponinas, resinas e alcalóides). A dosagem de fenóis totais $(\mathrm{FT})$ foi realizada pelo teste de Folin-Ciocalteu, seguindo a metodologia adaptada por McDonald et al. (2001). O teor de FT foi determinado por interpolação da absorbância das amostras contra a curva de calibração construída com padrões de ácido gálico. Os resultados, determinados a partir da equação de regressão da curva de calibração $\quad\left(y=0,02 x-0,0064 ; R^{2}=\right.$ 0,9911), foram expressos em miligramas de ácido gálico equivalentes por grama da amostra. A dosagem de artemisinina foi realizada no laboratório de fitoquímica do CPQBA-UNICAMP, pelo método de cromatografia líquida de alta eficiência (CLAE), seguindo a metodologia descrita por Celeghini et al. (2009), com tempo de retenção para quantificação da artemisinina de 7,5 min. A atividade toxicidade do extrato foi avaliada através do teste de letalidade frente à Artemia salina Leach, seguindo a metodologia de Meyer et al. (1982). O critério de toxicidade dos extratos foi estabelecido segundo o mesmo autor, sendo valores abaixo de $1000 \mu \mathrm{g} / \mathrm{mL}$ (tóxicos), entre 500 e $1000 \mu \mathrm{g} / \mathrm{mL}$ (fracamente tóxico) e acima de 1000 $\mu \mathrm{g} / \mathrm{mL}$ (não tóxicos). $O$ ensaio antioxidante foi realizado pelo método de redução do radial livre DPPH $(1,1-$ difenil-2-picril-hidrazila), de acordo com o metodologia de Blois (1958), usando como padrão o ácido ascórbico.

\section{Teste de eclodibilidade de ovos}

(TEO). Inicialmente se procede com a recuperação dos ovos. Para tal, foram colhidas fezes diretamente da ampola retal de caprinos, previamente selecionados, com contagem de OPG superior a 4000 . Um pool de 60 gramas de fezes foi processado conforme o protocolo de Coles et al. (1992), adaptado por Bizimenyera et al. (2006). As fezes foram maceradas e homogeneizadas em água aquecida a $40^{\circ} \mathrm{C}$ e filtradas em uma sequência de peneiras com malhas contendo aberturas de $400,250,150,75$ e $25 \mu \mathrm{m}$. Após esta lavagem, os ovos foram coletados da última peneira e distribuídos em tubos de $50 \mathrm{~mL}$ e centrifugados em $3000 \mathrm{rpm}$ por 3 minutos. Em seguida, foi descartado o sobrenadante e o volume total do tubo foi completado com solução salina saturada para a ressuspensão do sedimento. Novamente o material foi centrifugado e o sobrenadante foi lavado na peneira de $25 \mu \mathrm{m}$ com água destilada, até a retirada total da solução salina. O conteúdo foi transferido para um Becker e quantificado em alíquotas de $50 \mu \mathrm{L}$, com aproximadamente 200 ovos.

O protocolo utilizado para o TEO foi descrito por Coles et al. (1992), 
modificado por Bizimenyera et al. (2006). Para seguir a adaptação, aproximadamente $50 \mu \mathrm{L}$ da suspensão contendo 200 ovos foram acondicionados em cada poço em placas de 24 poços. Calculado o volume final de $1 \mathrm{~mL}$ para cada poço, os tratamentos fitoterápicos foram preparados nas concentrações de: 50 ; $25 ; 12.5 ; 6.25 ; 3.125 ; 1.562$ e 0.781 $\mathrm{mg} / \mathrm{mL}$. O extrato foi diluído com $3 \%$ de DMSO. O controle negativo foi feito com água destilada, já os controles positivos foram realizados com o emulsificante DMSO aquoso a $3 \%(\mathrm{v} / \mathrm{v})$ e o outro com albendazol $0,63 \mathrm{mg} / \mathrm{mL}$. A contagem dos ovos e das larvas foi realizada em microscópio invertido. Seis réplicas foram realizadas para cada tratamento e também para os controles. No cálculo da eficácia, utilizou-se a seguinte fórmula:

Percentual de eclodibilidade $(\%)=\mathrm{L} 1 /$ (ovos + L1) $\times 100$

Teste de Desenvolvimento Larvar (TDL). Para a obtenção das larvas de primeiro estádio (L1), obtevese uma alíquota de suspensão de ovos, conforme método descrito por Hubert e Kerboeuf, (1992), a qual posteriormente foi incubada por 24 horas em estufa a $37^{\circ} \mathrm{C}$. O TDL foi realizado seguindo a medotologia descrita por Roberts e O'Sullivan, (1950), modificado. Uma alíquota de $1 \mathrm{~mL}$, contendo aproximadamente $230 \quad \mathrm{~L} 1$ de $H$. contortus, foi incubada por 6 dias com 2 $\mathrm{g}$ de fezes de um animal livre de infecção parasitária, juntamente com 1 $\mathrm{mL}$ do $\mathrm{H} .7$ nas concentrações $50 ; 25$; $12.5 ; 6.25 ; 3.125 ; 1.562$ e $0.781 \mathrm{mg} / \mathrm{mL}$. $\mathrm{O}$ controle negativo foi feito com água destilada, já os controles positivos foram realizados com o emulsificante DMSO aquoso a $3 \%(\mathrm{v} / \mathrm{v})$ e o outro com ivermectina $(0,63 \mathrm{mg} / \mathrm{mL})$. Seis réplicas foram realizadas para cada tratamento $e$ também para os controles.

Análise estatística. A análise estatística foi realizada com a análise de variância (ANOVA), seguido do teste de Tukey, onde foram considerados estatisticamente diferentes os resultados que apresentaram probabilidade de ocorrência da hipótese de nulidade menor que $5 \%(P<0,05)$. Todas as análises foram realizadas usando o programa GraphPad Prism ${ }^{\circledR} 5$.

\section{RESULTADOS E DISCUSSÃO}

$\mathrm{Na}$ marcha fitoquímica, foram detectadas a presença de alcalóides, catequinas, esteróides, fenóis, resinas, taninos e triterpenos. Antocianinas, antocianidinas e leucoantocianidinas não foram encontradas no teste utilizado. O teor de fenóis totais, em equivalentes de ácido gálico, foi de $203,0 \pm 0,569 \mu \mathrm{g} / \mathrm{L}$. A concentração de artemisinina foi de $59,41 \pm 1,47 \mu \mathrm{g} / \mathrm{dl}$. O teste de toxicidade frente a $A$. salina apresentou DL50 de $3,827 \mu \mathrm{g} / \mathrm{mL}$ (R2= 0,9478). No ensaio antioxidante foi demonstrado que $640 \mu \mathrm{g} / \mathrm{mL}$ possui $98,76 \%$ da atividade antioxidante do padrão ácido ascórbico, o qual foi escolhido por ser um dos três compostos químicos com maior atividade conhecidos.

Os resultados do TEO e TDL estão apresentados no Quadro 1. No TEO, na concentração de $50 \mathrm{mg} / \mathrm{mL}$ foi encontrado $93,22 \%( \pm 1,87)$ de eficácia, sendo este valor semelhante ao controle positivo $(98,12 \pm 0,76 \%) \quad(P<0,05)$. No TDL, na concentração de $50 \mathrm{mg} / \mathrm{mL}$ foi 
encontrado $90,33 \%( \pm 0,27)$ de eficácia, o qual foi semelhante ao controle positivo deste teste $(97,84 \pm 0,54 \%)$ $(\mathrm{P}<0,05)$. Os resultados, em ambos os testes, demonstraram um efeito dosedependente, nos quais quanto maior a concentração dos extratos, maior o efeito sobre os ovos/TEO e larvas/TDL, respectivamente.

\section{DISCUSSÃO}

$\mathrm{Na}$ procura por antiparasitários naturais, os testes in vitro em fases nãoparasitárias são fundamentais para fazer uma análise preliminar de princípios originários de material vegetal, dos seus compostos químicos e sua ação. Com a grande quantidade de vegetais e compostos sintéticos sendo investigados, os métodos in vitro destacam-se por seu baixo custo e tempo empregados, além de não serem utilizados animais experimentais (Fortes et al., 2014).

$\mathrm{Na}$ marcha fitoquímica, os compostos encontrados nos testes qualitativos e a concentração de artemisinina e fenóis totais observados corroboram com os expostos na literatura científica (Brisibe et al. 2009). Dentre os principais responsáveis pela atividade anti-helmíntica da $A$. annua, destacam-se os flavonóides, taninos e artemisinina (O'Neill et al., 2010). Todavia, as cumarinas, compostos esteróides, fenóis, purinas e triterpenóides são imunomoduladores, melhoram a absorção do fitoterápico e permitem prolongar a permanência no organismo (Brisibe et al., 2009).

O mecanismo de ação dos flavonóides frente aos parasitas ocorre indiretamente, devido ao fato deste composto ser o maior responsável pela atividade antioxidante da planta, sendo assim, possui efeito direto sobre a redução do envelhecimento celular e melhora da imunidade (Lakshimi et al., 2010). Enquanto os taninos possuem um efeito anti-helmíntico pronunciado, principalmente por reduzir a taxa metabólica do parasito, reduzindo a disponibilidade de nutrientes (Hoste et al., 2006). Também ocorre aumento da biodisponibilidade de proteínas no organismo do animal, levando a uma maior resposta imune sobre parasitos intestinais. Especificamente para helmintos, há redução da fertilidade das fêmeas adultas e eclodibilidade dos ovos, além da diminuição da motilidade das larvas, o que pode diminuir a taxa de contaminação da pastagem (Molan et al., 2003). A artemisinina, principal biocomposto com atividades farmacológicas da planta, também chamada de qinghaosu, interfere nas proteínas mitocondriais de transporte do parasito e modula beneficamente 0 sistema imune do hospedeiro (Hoste et al., 2010).

A $A$. annua possui uma alta atividade antioxidante, principalmente devido ao elevado conteúdo fenólico presente na planta, sendo a maioria pertencente ao grupo dos flavonóides (Ferreira et al., 2010). Para fitoterápicos testados in vivo, uma elevada atividade antioxidante é uma característica desejável, tanto pela defesa direta do organismo e os danos oxidativos, quanto pela melhoria do estado imunológico do animal (Yuan et al., 2009).

Mesmo existindo diversos estudos evidenciando 0 efeito antiparasitário dos extratos produzidos a partir de $A$. annua, nunca houve 
pesquisas visando elucidar a ação in vitro frente ao $H$. contortus. O extrato demonstrou desempenho promissor, mesmo quando comparado com os controles positivos, o que evidencia a potente atividade anti-helmíntica da planta.

O H.7 demonstrou atividade de inibição da eclodibilidade de ovos com característica dose-dependente e atingiu eficácia superior a $90 \%$ nas concentrações de 25 e $50 \mathrm{mg} / \mathrm{mL}$. Diversos compostos fitoterápicos, produzidos a partir de diferentes plantas, já foram testados no TEO com ovos de $H$. contortus. $O$ extrato aquoso de Anacardia humile demonstrou inibição da eclosão dos ovos de 90,9\% em dosagem de $100 \mathrm{mg} / \mathrm{mL}$. (Nery et al., 2010). Extratos aquosos produzidos com as folhas de Syzygium cumini, Genipa americana e Solanum lycocarpum inibiram, respectivamente, 96,17; 18,27 e 14,2\% a eclodibilidade dos ovos de $H$. contortus, ao serem utilizados na concentração de 100 $\mathrm{mg} / \mathrm{mL}$ (Oliveira, 2013). O extrato aquoso produzido com folhas e frutos de Myrsine africana na concentração de 24 $\mathrm{mg} / \mathrm{mL}$ obteve eficácia de $77 \%$ (Gathuma et al., 2004). Extrato hidroalcoólico de Tarenaya spinosa inibiu a eclosão de $81,53 \%$ dos ovos do referido parasito, quando utilizado na dosagem de $150 \mathrm{mg} / \mathrm{mL}$. (Andrade et al., 2014).

O H.7 inibiu mais de $90 \%$ o desenvolvimento larval, quando usado na concentração de $50 \mathrm{mg} / \mathrm{mL}$, sendo seu efeito igualmente dose-dependente. É importante enfatizar, que os resultados encontrados no TEO são superiores ao TDL, em todas as concentrações testadas, o que também foi observado em grande parte da literatura científica consultada. Em trabalho realizado utilizando óleo essencial de Eucalyptus globulus na concentração de $43,5 \mathrm{mg} / \mathrm{mL}$ foi demonstrado $98,7 \%$ de inibição do desenvolvimento larval (Macedo et al., 2009). Utilizando a concentração de $50 \mathrm{mg} / \mathrm{mL}$ de extratos hexânico produzidos com folhas de Melia azedarach; obteve-se eficácia de 67,9\% no TDL (Maciel et al., 2006). O extrato acetato de etila de Azadirachta indica inibiu o desenvolvimento larvar em $68,10 \%$ na concentração de $50 \mathrm{mg} / \mathrm{mL}$ (Costa et al., 2008). Em estudo conduzido por Oliveira et al., 2010, o extrato aquoso de folhas, pseudocaules e corações de Musa spp., avaliado na concentração de $57,76 \mathrm{mg} / \mathrm{mL}$ apresentou eficácia de $90 \%$.

Além da avaliação do potencial anti-helmíntico de um composto é imprescindível ponderar seus possíveis efeitos tóxicos quando usados in vivo. Para estabelecer a toxicidade de $A$. annua foi usado o ensaio de letalidade da $A$. salina, teste que possui alta confiabilidade para avaliar o efeito tóxico de fitoterápicos com propriedades antiparasitárias (Fernández-Calienes Valdés et al., 2009). O resultado observado apontou que o $\mathrm{H} .7$ possui baixa toxicidade ( $D L 50>1,000 \mu \mathrm{g} / \mathrm{mL}$ ), sugerindo uma grande margem de biossegurança.

\section{CONCLUSÃO}

Com base nos resultados obtidos, concluiu-se que o extrato de $A$. annua obtido pela metodologia descrita no presente experimento, demonstramos ser candidato a fitoterápico antiparasitário para combater $H$. 
contortus. Novos estudos devem ser realizados buscando maximizar a eficácia do produto e posteriormente aplicá-lo em testes in vivo.

\section{REFERÊNCIAS}

ANDRADE, F.D.; RIBEIRO, A.R.C.; MEDEIROS, M.C.; FONSECA, S.S.; ATHAYDE, A.C.R.; FERREIRA, A.F.; ONALDO, G.R.; SILVA, W.W. Anthelmintic action of the hydroalcoholic extract of the root of Tarenaya spinosa (Jacq.) Raf. for Haemonchus contortus control in sheep. Pesquisa Veterinária Brasileira, v. 34, p. 942-946, 2014.

BIZIMENYERA, E.S.; GITHIORI, J.B.; ELOFF, J.N.; SWAN, G.E. In vitro activity of Peltophorum africanum Sond. (Fabacea) extracts on the egg hatching and larval development of the parasitic nematode Trichostrongylus colubriformis. Veterinary Parasitology, v. 142, p. 336-343, 2006.

BLOIS, M.S. Antioxidant determinations by the use of a stable free radical. Nature, v. 181, p. 1199-1200, 1958.

BRISIBE, E.A.; UMOREN, U.E.; BRISIBE, F.; MAGALHÃES, P.M.; FERREIRA, J.F.; LUTHRIA, D.; WU, X.; PRIOR, R.L. Nutritional characterisation and antioxidant capacity of different tissues of Artemisia annua L. Food Chemistry, v. 115, p. 1240-1246, 2009.

BRISIBE, E.A.; UMOREN, U.E.; OWAI, P.U.; BRISIBE, F. Dietary inclusion of dried Artemisia annua leaves for management of coccidiosis and growth enhancement in chickens. African Journal of Biotechnology, v. 7, p. 40834092, 2008.

CELEGHINI, R.M.D.S.; SOUSA, I.M.D.O.; SILVA, A.P.D.; RODRIGUES, R.A.F.; FOGLIO, M.A. Development and validation of analytical methodology by
HPLC-IR for evaluation of artemisinin on Artemisa annua L. Química Nova, v. 32, p. 875-878, 2009.

COLES, G.C.; BAUER, C.; BORGSTEEDE, F.H.M.; GEERTS, S.; KLEI, T.R.; TAYLOR, M.A.; WALLER, P.J. World Association for the Advancement of Veterinary Parasitology (WAAVP) - methods for detection of anthelmintic resistance in nematodes of veterinary importance. Veterinary Parasitology, v. 44, p. 35-44, 1992.

COSTA, C.T.C.; BEVILAQUA, C.M.L.; CAMURÇA-VASCONCELOS, A.L.F.; MACIEL, M.V.; MORAIS, S.M.; CASTRO, C.M.S.; BRAGA, R.R.; OLIVEIRA, L.M.B. In vitro ovicidal and larvicidal activity of Azadirachta indica extracts on Haemonchus contortus. Small Ruminant Research, v. 74, p.284-287, 2008.

FERNÁNDEZ-CALIENES VALDÉS, A.; MENDIOLA MARTÍNEZ, J.; MONZOTE FIDALGO, L.; GARCÍA PARRA, M.; SARIEGO RAMOS, I.; ACUÑA RODRÍGUEZ, D.; LIZAMA, R.S.; GUTIÉRREZ GAITÉN, Y. Evaluación de la toxicidad de extractos de plantas cubanas con posible acción antiparasitaria utilizando larvas de Artemia salina L. Revista Cubana de Medicina Tropical, v. 61, p. 254-258, 2009.

FERREIRA, J.F. ; LUTHRIA, D.L. ; SASAKI, T. ; HEYERICK, A. Flavonoids from Artemisia annua L. as antioxidants and their potential synergism with artemisinin against malaria and cancer. Molecules, v. 15, p. 3135-3170, 2010.

FORTES, F.S.; KLOSTER, F.S.; SCHAFER, A.S.; BIER, D.; BUZATTI, A.; YOSHITANI, U.Y.; MOLENTO, M.B. Avaliação da resistência em um isolado de campo selecionado de Haemonchus contortus à ivermectina e moxidectina usando o Teste de Migração de Larvas 
em Ágar. Pesquisa Veterinária Brasileira, v.33, p. 183-187, 2014.

GATHUMA, J.M.; MBARIA, J.M.; WANYAMA, J.; KABURIA, H.F.A.; MPOKE, L.; MWANGI, J.N. Efficacy of Myrsine africana, Albizia anthelmintica and Hilderbrantia sepalosa herbal remedies against mixed natural sheep helminthosis in Samburu district, Kenya. Journal of Ethnopharmacology, v. 91, p. 7-12, 2004.

HOSTE, H.; JACKSON, F.; ATHANASIADOU, S.; THAMSBORG, S.M.; HOSKIN, S.O. The effects of tannin-rich plants on parasitic nematodes in ruminants. Trends in Parasitology, v. 22, p. 253-261, 2006.

HOSTE, H.; SOTIRAKI, S.; LANDAU, S.Y.; JACKSON, F.; BEVERIDGE, I. Goat- nematode interactions: think differently. Trends in Parasitology, v. 26, p. 376-381, 2010.

HUBERT, J.; KERBOEUF, D. A microlarval development assay for the detection of anthelmintic resistance in sheep nematodes. Veterinary Record, v. 130, p. 442-446, 1992.

KEISER, J.; UTZINGER, J. Artemisinins and synthetic trioxolanes in the treatment of helminth infections. Current Opinion in Infectious Diseases, v. 20, p.605-612, 2007.

LAKSHMI, V.; JOSEPH, S.K.; SRIVASTAVA, S.; VERMA, S.K.; SAHOO, M.K.; DUBE, V.; MURTHY, P.K. Antifilarial activity in vitro and in vivo of some flavonoids tested against Brugia malayi. Acta Tropical, v. 116, p. 127-133, 2010.

MACEDO, I.T.; BEVILAQUA, C.M.; OLIVEIRA, L.D.; CAMURÇAVASCONCELOS, A.L.; VIEIRA, L.D.S.; OLIVEIRA, F.R.; BARROS, R.S.;
CHAGAS, A.C. Atividade ovicida e larvicida in vitro do óleo essencial de Eucalyptus globulus sobre Haemonchus contortus. Revista Brasileira de Parasitologia Veterinária, v. 18, p. 6266, 2009.

MACIEL, M.V.; MORAIS, S.M.; BEVILAQUA, C.M.L.; CAMURÇAVASCONCELOS, A.L.F.; COSTA, C.T.C.; CASTRO, C.M.S. Ovicidal and larvicidal activity of Melia azedarach extracts on Haemonchus contortus. Veterinary Parasitology, v. 140, p. 98-104, 2006.

MATOS, F.J.A. Farmácias vivas. 3 ed. Fortaleza: Edições UFC, 1998. 220 p.

MCDONALD, S.; PRENZLER, P.D.; ANTOLOVICH, M.; ROBARDS, K. Phenolic content and antioxidant activity of olive extracts. Food Chemistry, v. 73, p. 73-84, 2001.

MEYER, B.N.; FERRIGNI, N.R.; PUTNAM, J.E.; JACOBSEN, L.B.; NICHOLS, D.E.; MCLAUGHLIN, J.L. Brine shrimp: a convenient general bioassay for active plant constituents. Planta Medica, v. 45, p. 3134, 1982.

MOLAN, A.L.; DUNCAN, A.J.; BARRY, T.N.; MCNABB, W.C. Effects of condensed tannins and crude sesquiterpene lactones extracted from chicory on the motility of larvae of deer lungworm and gastrointestinal nematodes. Parasitology, v. 52, p. 209218, 2003.

MOLENTO, M. B. Resistência parasitaria em helmintos de equídeos e propostas de manejo. Ciência Rural, v. 35, p. 1469-1477, 2005.

NERY, P.S.; NOGUEIRA, F.A.; MARTINS, E.R.; DUARTE, E.R. Effects of Anacardium humile leaf extracts on the development of gastrointestinal 
nematode larvae of sheep. Veterinary

Parasitology, v. 171, p. 361-364, 2010.

O'NEILL, P.M.; BARTON, V.E.; WARD, S.A. The molecular mechanism of action of artemisinin - The debate continues. Molecules, v. 15, p. 1705-1721, 2010.

OLIVEIRA, L.D.R. Plantas medicinais como alternativa para o controle de Haemonchus contortus em ovinos: testes in vitro e in vivo. Dissertação de Mestrado em Ciências Animais, Universidade de Brasília, Brasília, DF. 59p, 2013.

OLIVEIRA, L.N.; DUARTE, E.R.; NOGUEIRA, F.A.; SILVA, R.B.; FILHO, D.E.F; GERASEEV, L.C. Eficácia de resíduos da bananicultura sobre a inibição do desenvolvimento larval em Haemonchus spp. provenientes de ovinos. Ciência Rural, v. 40, p. 488-490, 2010.

ROBERTS, F.H.S.; O'SULLIVAN, P.J. Methods for egg counts and larval cultures for strongyles infesting the gastro-intestinal tract of cattle. Crop Past. Science, v.1, p. 99-102, 1950.

YUAN, C.; HUANG, X.; CHENG, L.; BU, Y.; LIU, G.; YI, F.; SONG, F. Evaluation of antioxidant and immune activity of Phellinus ribis glucan in mice. Food Chemistry, v. 115, p. 581-584, 2009. 